\title{
Ekmeklik Buğdayda (Triticum aestivum L.) Tane Verimi ile Bazı Tarımsal Karakterler Arası İlişkiler
}

\author{
*İrfan Öztürk \\ Remzi Avcl \\ Trakya Tarımsal Araştırma Enstitüsü Müdürlüğü, Edirne \\ *Sorumlu yazar e-posta (Corresponding author; e-mail): irfanozturk62@hotmail.com
}

Geliş Tarihi (Received): 19.07.2014

Kabul Tarihi (Accepted): 27.10.2013

\section{Öz}

Araştırma, bazı ekmeklik buğday çeşitlerinin verim, bazı tarımsal ve fizyolojik özelliklerinin belirlenmesi amacıyla 2009-2010 ve 2010-2011 yıllarında Edirne'de yürütülmüştür. Deneme 22 çeşit ile tesadüf blokları deneme desenine göre 4 tekrarlamalı olarak kurulmuştur. Tane verimi, bayrak yaprak alanı, bitki örtüsü sıcaklığı, bayrak yaprak klorofil miktarı, yaprak su tutma kapasitesi, kuru madde oranı, bitki boyu, başaklanma ve olgunlaşma gün sayıları gibi özellikler incelenmiştir.

Araştırmada tane verimi dışında diğer karakterlerde çeşitler arasında önemli istatistiksel farklılıklar bulunmuştur. Çeşitlerin genel ortalama tane verimi $721,8 \mathrm{~kg} / \mathrm{da}$ olurken, en yüksek tane verimi $762,3 \mathrm{~kg} / \mathrm{da}$ ile Trakya BVD7 hattında belirlenmiştir. En geniş bayrak yaprak $32,96 \mathrm{~cm}^{2}$ ile Tina, en az yaprak alanı ise 18,54 cm² $^{2}$ ile Kate A-1 çeşidinde ölçülmüştür. Araştırmada kanopi sıcaklığı ve bayrak yaprakta klorofil ölçümü başaklanma döneminde yapılmıştır. Kanopi sıcaklığı $22,66{ }^{\circ} \mathrm{C}$ ile $25,75{ }^{\circ} \mathrm{C}$ arasında değişmiş, en yüksek sıcaklık Tina, en düşük sıcaklık ise Milena çeşidinde ölçülmüştür. En fazla klorofil miktarı 53,41 ile Tekirdağ, en düşük 46,89 ile Golia çeşidinde ölçülmüştür. En fazla yaprak su tutma kapasitesi Bereket, en fazla kuru madde oranı ise Tekirdağ çeşidinde belirlenmiştir. Kanopi sıcaklığı ile bayrak yaprak alanı arasında yüksek oranda pozitif olumlu ilişki saptanırken $(r=0,628)$, bitki boyu ile $(r=-0,459)$ ve yaprak su tutma kapasitesi $(r=-0,355)$ olumsuz ilişki belirlenmiştir. Bitki boyu ile klorofil miktarı $(r=0,398)$ ve yaprak su tutma kapasitesi arasında $(r=0,371)$ düşük oranda olumlu ilişki belirlenmiştir. Araştırma sonuçlarına göre, Trakya BVD7 ve Nina yüksek tane verimi ile öne çıkan genotipler olmuştur. Tane verimi ile fizyolojik karakterler arasında beklenen ilişkiyi görebilmek için fizyolojik çalışmalar kurak koşullarda yürütülmelidir.

Anahtar Kelimeler: Ekmeklik buğday, çeşit, verim, fizyolojik karakter.

\section{An Assessment on Grain Yield vs. Some Agronomic Characteristics in Bread Wheat (Triticum aestivum L.)}

\begin{abstract}
This study was carried out to determine grain yield, some agricultural and physiological characteristics of the some bread wheat varieties in 2009-2010 and 2010-2011 growing seasons in Edirne. Experiment was set up with 22 cultivars employing completely randomized blocks design with four replications. The characteritics such as grain yield, flag leaf area, canopy temperature, chlorophyll content of flag leaf, water content and dry matter of flag leaf, plant height, days to heading and maturating were scored.

Except grain yield all other characteristics were statistically significant. The two year average grain yield of all varieties was $721.8 \mathrm{~kg} / \mathrm{da}$. The highest grain yield $(762.3 \mathrm{~kg} / \mathrm{da})$ was obtained from Trakya BVD7 . Tina variety gave the widest flag leaf area $\left(32.96 \mathrm{~cm}^{2}\right)$, while the lowest leaf area was measured in Kate A-1 variety with $18.54 \mathrm{~cm}^{2}$. Measurements of canopy temperature and chlorophyll content in flag leaf were performed at heading stage. Canopy temperature varied between $22.66^{\circ} \mathrm{C}$ and $25.75^{\circ} \mathrm{C}$, the highest canopy temperature was measured for Tina and, the lowest was for Milena cultivar. The highest and lowest chlorophyll contents (53.41 and 46.89) were measured in Tekirdağ and Golia cultivars respectively. Bereket and Tekirdağ varieties gave the highest leaf water content and dry matter values, respectively. Although canopy temperature positively correlated with flag leaf area, it turned out to be negative with plant height $(r=-0,459)$ and leaf water content $r=-0,355)$. Coeffiicinet of correlation between plant height vs.chlorophyll content and leaf water content were positive but insignificant. Trakya BVD7, and Nina were prominent genotypes with their highest yielding capacities based on the result of the study. Relationship between grain yield versus physiological traits should be further carried out under drought conditions.
\end{abstract}

Key Words: Bread wheat, genotypes, yield, physiological traits. 


\section{Giriş}

T rakya, yüksek verim potansiyeli ile ekmeklik buğday üretiminde önemli bir bölgedir. Trakya Bölgesinde yıldan yıla değişmekle birlikte ortalama hububat ekimi 650.000 hektardır (Anonim, 2011). Trakya Bölgesi ülkemizin buğday ekiliş oranının yaklaşık olarak $\%$ 5-7'sini, üretiminin ise \% 11-13'ünü karşılamaktadır (Anonim, 2011). Ayrıca, bölgenin ortalama buğday verimi Türkiye ortalaması ile kıyaslandığında bölge ortalamasının Türkiye ortalamasından \% 70-80 daha fazla olduğu görülmektedir. Bu veriler bölge için buğday tarımının önemini ortaya koymaktadır. Bölgenin ortalama verimi yüksek olmasına rağmen özellikle Nisan ve Mayıs ayalarındaki yağışın yetersiz veya düzensiz olması verim düşüklüğüne neden olmaktadır. Verim düşüklüğü özellikle kumsal ve organik maddece düşük topraklarda daha belirgin şekilde görülmektedir (Öztürk ve Korkut, 2011). Kurak koşullarda bitkilerde kurağa dayanıkılık ıslah programının önemli bir bölümünü oluşturmaktadır. Olgunlaşma süresinin kısa olması veya bitkilerdeki erken çiçeklenme özellikle geç dönem kuraklıklarından kaçma açısından ıslaha katkı sağlayan önemli bir karakterdir. Kuraklık stresi altında ölçülen kanopi sıcaklığı kurak koşullarda bitki bünyesindeki su durumunu belirten bir yöntemdir. Kurak şartlardaki düşük kanopi sıcaklığı değeri bitki bünyesinin yeterli su oranına sahip olduğunu belirtmektedir (Blum, 2000). Kuraklık stresi olmayan normal koşullarda genotipler arasındaki kanopi sıcaklığında çok az fark olurken, kuraklık stresinin yaşandığı koşullarda genotiplerde kanopi sıcaklıkları farkında artış olmaktadır (Blum, 2000). Stres koşullarında kanopi sıcaklığı ile verim arasında ters ilişki bulunmuştur. Yaprak rengi yaprağın sıcaklık özelliğini etkileyebilir. Açık yeşil-sarı yaprağa sahip buğday ve arpa çeşitlerinde normal renkli olanlara göre yaklaşık üçte bir oranında daha az klorofile sahiptir (Blum, 2000). Bu yapraklar normal yeşil renkli olanlara göre sıcaklığı daha fazla yansıttığı için daha düşük sıcaklığa sahiptirler. Bu nedenle sarı yapraklı çeşitler kurak koşullara daha uyum sağlama eğilimindedir (Blum, 2000). Bitkilerde klorofil kaybının tane doldurma süresince devam etmesi verim düşüşüyle ilişkili olup, fizyolojik mekanizmalardan uzun süre yeşil kalabilme kabiliyeti ve yüksek fotosentez oranı gibi metabolizmalar sıcaktan kaçma özelliği olarak ortaya çıkmaktadır (Reynolds ve ark., 2001). Tahıllarda başaklanma zamanı bakımından erkenci olan çeşitler tercih edilmekte ve erkencilik denildiği zaman daha çok başaklanma tarihi ifade edilmektedir. Buna rağmen başaklanma ile fizyolojik olum süresinin kısa olması verimlilik açısından istenmeyen bir durumdur (Soylu ve Sade, 2000). Trakya gibi yarı kurak bölgelerde buğdaydan yüksek tane verimi eldesinde en önemli seleksiyon ölçütleri yaprak su tutma kabiliyeti olup, bu özelliğin yanında tane dolum süresi, bayrak yaprak alanı ve stoma sayısının da göz önüne alınması gerekmektedir (Başer ve ark., 2005). Araştırmada Trakya Bölgesinde üretimi yapılan bazı çeşitlerin verim, çeşitli morfolojik ve fizyolojik karakterleri ile bu özellikler arasındaki ilişkiler incelenmiştir.

\section{Materyal ve Yöntem}

Araştırmada Trakya Bölgesinde üretimi yapılan bazı ekmeklik buğday çeşitleri ile yeni geliştirilen hatlar yer almış, 2009-2010 ve 20102011 yıllarında Trakya Tarımsal Araştırma Enstitüsü deneme tarlasında yürütülmüştür. Denemede 22 genotip tesadüf blokları deneme desenine göre 4 tekrarlamalı olarak, ekimde parsel alanı $7 \mathrm{~m}^{2}$ ve hasatta $6 \mathrm{~m}^{2}$, metrekareye 500 tane tohum olacak şekilde ekimi yapılmıştır. Araştırmada; tane verimi, bitki boyu, başaklanma ve olgunlaşma gün sayıları ile bitki örtüsü sıcaklığı, bayrak yaprakta klorofil miktarı, yaprak su tutma kapasitesi, kuru madde miktarı özellikleri incelenmiştir. Başaklanma gün sayısı her parselde bitkilerin \% 50'sinde başaklanmanın gerçekleştiği, olgunlaşma gün sayısı ise parselde bitkilerin tamamının sarardığı zaman dikkate alarak belirlenmiştir. Bitki boyu her parselde sarı olum döneminde parselin farklı yerinden 10 adet bitkide ölçüm yapılarak tespit edilmiştir. Bitki örtü sıcaklığı (Kanopi), Jackson ve ark. (1981)'nın önerdiği yönteme göre, infrared termometre ile derece $\left({ }^{\circ} \mathrm{C}\right)$ cinsinden ölçülmüştür. Bu yöntemde başaklanma döneminde 12:00-15:00 saatleri arasında okuma yapılmıştır. Bayrak yaprağın klorofil miktarı SPAD biriminde başaklanma döneminde ölçüm yapılmıştır (Adamsen ve ark. 1999). Her parselde 10 adet bayrak yaprakta 30 ölçüm yapılarak ortalaması alınmıştır. Yaprak su tutma kapasitesi Clarke (1982) tarafından verilen yönteme göre başaklanma döneminde bayrak yaprağın önce yaş ağırlığı tartılmış, daha sonra bu yapraklar $30^{\circ} \mathrm{C}$ 'de 2 saat kurutulduktan sonra tekrar tartılarak aradaki fark 
yaprak su tutma kapasitesi olarak belirlenmiştir. Kuru madde miktarı yaprak su tutma kapasitesinin belirlenmesi için alınan yaprak örnekleri $30{ }^{\circ} \mathrm{C}$ 'de 2 saat kurutulduktan sonra aynı örnekler $105^{\circ} \mathrm{C}$ 'de 24 saat kurutulduktan sonra tekrar tartılarak kuru madde miktarı hesaplanmıştır.

Finlay ve Wilkinson (1963) tarafından adaptasyon yeteneğinin her genotipe ait ortalama değerin, tümünün ortalamasına olan doğrusal regresyondan saptanabileceği bildirilmiştir. Ancak bu görüş daha sonraları değiştirilerek stabilitenin, ortalama, regresyon katsayısı ve regresyondan sapma değerleri ile bulunabileceği şeklinde uyarlanmıştır (Eberhart ve Russell, 1966). Stabilite parametresi olarak kullanılan en yaygın metotlardan biri regresyon katsayısıdır (Finlay ve Wilkinson 1963; Eberhart ve Russell, 1966). Regresyon katsayısı 1'e ne kadar yakın ise genotipin stabilitesi o kadar yüksektir. Stabilite parametresi olarak regresyondan sapma da kullanılmış ve regresyondan sapması sıfıra yakın olan ve verim ortalaması genel ortalamadan yüksek genotipler stabil olarak kabul edilmiştir (Eberhart ve Russell, 1966). Araştırmanın yürütüldüğü yerde ölçülen bazı iklim değerleri Çizelge 1'de verilmiştir. Her iki yılın birleşik varyans analizleri ve ortalamaların gruplanması (AÖF) JMP5.0.1a istatistik programı kullanılarak yapılmıştır (Kalaycı, 2005).

\section{Bulgular ve Tartışma}

Araştırmada incelenen karakterlerde çeşitler arasında önemli farklılıklar bulunmuştur. Çeşitlerde tespit edilen tane verimi Çizelge 2'de verilmiş olup genotiplerin yıllar bazında genel ortalaması 721,8 kg/da olmuştur. Yapılan değerlendirmede en yüksek ortalama tane verimi
762,3 kg/da ile Trakya BVD7 çeşidinde belirlenirken bunu $752,3 \mathrm{~kg} / \mathrm{da}$ ile Tina çeşidi takip etmiştir. Nina, Selimiye, Syrena Prostor ve Gelibolu çeşitlerinin de yüksek verim potansiyeline sahip olduğu görülmüştür. Tane veriminde çok önemli olan bayrak yaprak alanına göre genotipler arasındaki istatistiksel farklılık çok önemli (0.01) bulunmuştur. Araştırmada genotiplerin genel ortalaması $25,05 \mathrm{~cm}^{2}$ olurken, en geniş bayrak yaprak alanı $32,96 \mathrm{~cm}^{2}$ ile Tina çeşidinde, en az yaprak alanı $18,54 \mathrm{~cm}^{2}$ ile Kate A-1 çeşidinde belirlenmiştir. Başaklanma döneminde ölçülen bitki örtüsü sıcaklığına ait yapılan varyans analizi sonucuna göre genotipler arasında $22,66^{\circ} \mathrm{C}$ ile $25,75^{\circ} \mathrm{C}$ arasında değişim göstermiştir. Genotipler arasında yapılan değerlendirmede $25,75^{\circ} \mathrm{C}$ ile en yüksek bitki örtüsü sıcaklığı Tina çeşidinde ölçülürken, en düşük sıcaklık 22,66 ${ }^{\circ} \mathrm{C}$ ile Milena çeşidinde ölçülmüştür. Kanopi sıcaklığının uygun koşullar altında verim ile yüksek ilişkili olduğu (Van Ginkel ve ark. 2004), bitkilerin kurak ve sıcak şartlardaki bitki örtüsü sıcaklığı ile kurağa toleranslılığı arasında ilişki bulunmakta olduğu (Blum ve ark. 1989) belirtilirken bu araştırmanın doğal koşullarda yürütülmesi, kuraklık stresinin uygulanmaması neticesinde verim ile kanopi sıcaklığı arasında beklenen ilişki bulunmamıştır. Kanopi sıcaklığına göre genotipler arasında önemli farklılık bulunmuştur. Araştırmada kuraklık stresi uygulanmadığı için tane verimi ile kanopi sıcaklığı arasında herhangi bir ilişki tespit edilmemiştir. Uzun boylu çeşitlerde daha düşük kanopi sıcaklığı ölçümü yapılmıştır $\left(r=-0,459^{*}\right)$. Yine geççi çeşitlerde daha düşük ( $r=-0,255)$, erkenci çeşitlerde ise daha yüksek kanopi sıcaklığı ölçülmüştür. Ayrıca yaprak su tutma kapasitesindeki artış kanopi sıcaklığını düşürmüştür.

Çizelge 1. Edirne ili 2009-2010 ve 2010-2011 yılları bazı meteorolojik veriler

Table 1. Meteorological data for 2009-2010 and 2010-2011 growing seasons in Edirne

\begin{tabular}{lcccccccc}
\hline \multirow{2}{*}{ Aylar } & \multicolumn{3}{c}{ Yağıs $(\mathrm{mm})$} & \multicolumn{3}{c}{ Sıcaklık $\left({ }^{\circ} \mathrm{C}\right) \mathbf{2 0 0 9 - 2 0 1 0}$} & \multicolumn{2}{c}{ Sıcaklık $\left({ }^{\circ} \mathrm{C}\right) 2010-2011$} \\
\cline { 2 - 8 } & $2009-$ & $2010-$ & \multirow{2}{*}{ En az } & En fazla & Ortalama & En az & En fazla & Ortalama \\
\hline Eylül & 2010 & 2011 & & & & & & \\
Ekim & 74,1 & 31,4 & 6,6 & 36,9 & 19,9 & 9,0 & 33,8 & 21,2 \\
Kasım & 112,6 & 68,5 & 2,9 & 28,9 & 15,1 & $-0,7$ & 23,8 & 13,0 \\
Aralık & 51,7 & 39,7 & $-1,7$ & 22,7 & 9,7 & 1,3 & 23,7 & 13,5 \\
Ocak & 93,4 & 34,4 & $-2,1$ & 19,6 & 7,3 & $-8,3$ & 22,6 & 5,7 \\
Şubat & 59,6 & 34,4 & $-16,3$ & 20,3 & 2,5 & $-8,3$ & 22,6 & 5,7 \\
Mart & 107,0 & 45,8 & $-4,8$ & 20,3 & 5,9 & $-7,4$ & 11,7 & 2,5 \\
Nisan & 47,6 & 16,0 & $-3,1$ & 22,2 & 7,7 & $-6,1$ & 23,7 & 7,4 \\
Mayıs & 17,8 & 47,4 & 0,9 & 24,9 & 12,7 & $-0,9$ & 24,1 & 10,5 \\
Haziran & 16,0 & 12,4 & 3,3 & 33,6 & 18,1 & 2,9 & 31,8 & 17,4 \\
\hline Toplam/ & 30,8 & 32,4 & 12,0 & 38,7 & 22,5 & 11,3 & 34,4 & 21,9 \\
Ortalama & 610,6 & 362,4 & $-16,3$ & 38,7 & 12,1 & $-8,3$ & 34,4 & 11,9 \\
\hline
\end{tabular}


Çizelge 2. AÖF testine göre gruplanan karaterlerie ait ortalama değerler.

Table 2. Means of the some agonomical characteristics grouped by LSD test.

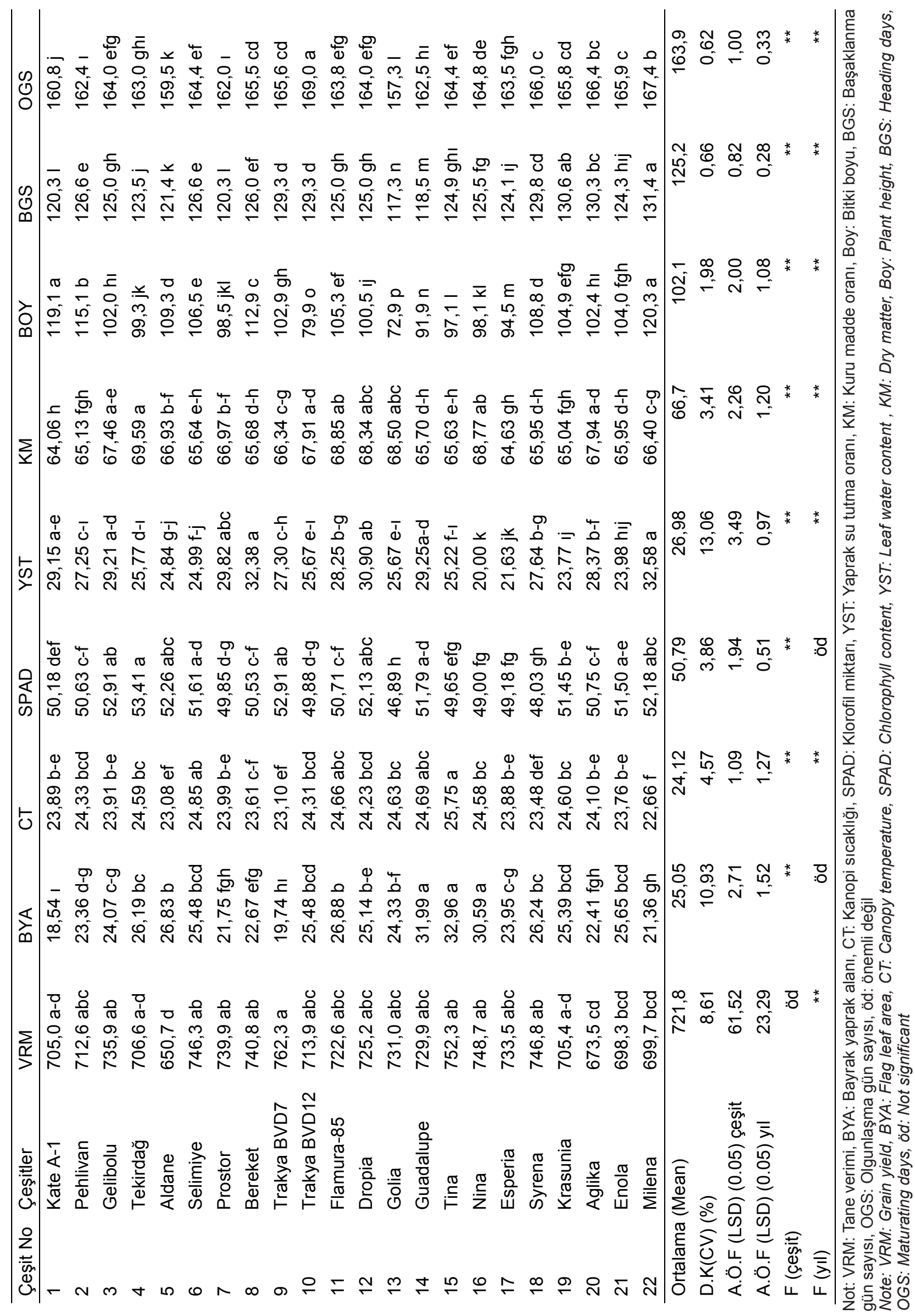




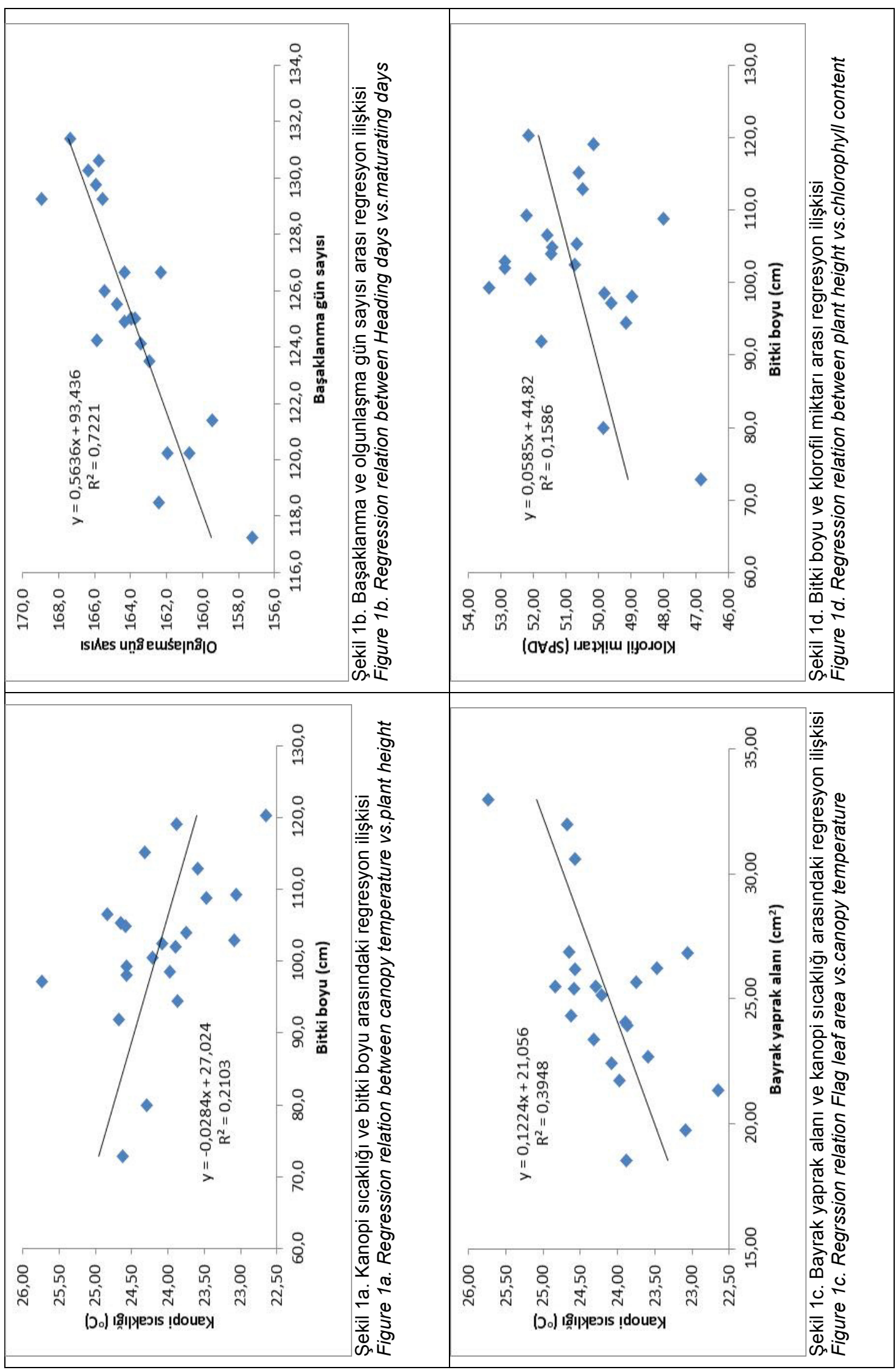

Şekil 1. Araştırmada incelenen verim ve bazı karakterlerin karşılaştırılması

Figure 1. Regression equations among some of characteristics 
Çizelge 3. Araştırmada incelenen karakterlerde tespit edilen korelasyon katsayıları

Table 3. The coefficients of correlation for grain yield and some characteristics

\begin{tabular}{|l|c|c|c|c|c|c|c|c|}
\hline Karakterler & VRM & BYA & CT & SPAD & YST & KM & BGS & OGS \\
\hline BYA & 0,151 & & & & & & & \\
\hline CT & 0,298 & $0,628^{* *}$ & & & & & & \\
\hline SPAD & $-0,284$ & $-0,122$ & $-0,249$ & & & & & \\
\hline YST & $-0,024$ & $-0,423$ & $-0,355$ & 0,276 & & & & \\
\hline KM & $-0,079$ & 0,205 & 0,149 & 0,066 & $-0,025$ & & & \\
\hline BGS & $-0,008$ & $-0,182$ & $-0,255$ & 0,200 & 0,042 & $-0,062$ & & \\
\hline OGS & 0,115 & $-0,007$ & $-0,148$ & 0,209 & 0,072 & $-0,032$ & $0,850^{* *}$ & \\
\hline BOY & $-0,233$ & $-0,365$ & $-0,459^{*}$ & 0,398 & 0,371 & $-0,439^{*}$ & 0,350 & 0,170 \\
\hline
\end{tabular}

Not: *: p<0.05; **: p<0.01 düzeyinde önemlidir. VRM: Tane verimi, BYA: Bayrak yaprak alanı, CT: Kanopi sıcaklığı, SPAD: Klorofil miktarı, YST: Yaprak su tutma oranı, KM: Kuru madde oranı, Boy: Bitki boyu, BGS: Başaklanma gün sayıSı, OGS Olgunlaşma gün sayısı.

Note: * ** significance at $p<0.05 ; p<0.01$ levels, respectively. VRM: Grain yield, BYA: Flag leaf area, CT: Canopy temperature, SPAD: Chlorophyll content, YST: Leaf water content, KM: Dry matter, Boy: Plant height, BGS: Heading days, OGS: Maturating days.

Araştırmada klorofil miktarının artması kanopi sıcaklığını düşürdüğü tespit edilmiştir ( $r=-0,249)$. Bayrak yaprakta ölçülen klorofil miktarı genotiplerde ortalama 50,79 olarak tespit edilmiştir. Genotipler arasında önemli farklılık $(P<0,01)$ tespit edilmiş olup, klorofil kapsamı en yüksek olan 53,41 ile Tekirdağ, 52,91 ile Trakya BVD7 ve Gelibolu çeşitleri olmuştur. En düşük klorofil miktarı ise 46,89 ile Golia 48,03 ile Syrena çeşitlerinde belirlenmiştir.

Araştırmada yapılan ikili ilişkide yaprak su tutma kapasitesi fazla olan çeşitler ile bitki boyu uzun olan çeşitlerde daha fazla klorofil miktarı tespit edilmiştir $(r=0,398)$. Çeşitlerde yaprak su tutma oranının tespiti başaklanma döneminde yapılmış olup istatistiki analiz sonucuna göre genotipler arasındaki fark 0.01 seviyesinde önemli bulunmuştur. Genotiplerde en fazla su tutma kapasitesi \% 32,58 ile Milena ve \% 32,38 ile Bereket çeşitlerinde tespit edilmiştir. Çalışmada en az yaprak su tutma kapasitesi \% 20,0 ile Nina ve \% 21,63 ile Esperia çeşitlerinde belirlenmiştir. Uzun boylu çeşitlerde daha yüksek yaprak su tutma kapasitesi saptanmıştır $(r=0,371)$.

Genotiplerde kuru madde miktarları başaklanma döneminde alınan bayrak yapraklarda belirlenmiş ve genotipler arasında önemli farklılık $(P<0,01)$ tespit edilmiştir. Genotipler düzeyinde en fazla kuru madde oranı $\%$ 69,59 ile Tekirdağ, \% 68,85 ile Flamura-85 ve $\%$ 68,77 ile Nina, en az kuru madde ise \% 64,06 ile Kate A-1 çeşidinde tespit edilmiştir.

Araştırmada bitki boyu bakımından çeşitler arasında önemli farklılık $(P<0,01)$ saptanmıştır. Ortalama bitki boyu 102,1 cm olarak belirlenirken, çeşitler arasında bitki boyu $72,9 \mathrm{~cm}$ ile $120,3 \mathrm{~cm}$ arasında dağılım göstermiştir. Uzun boylu çeşitlerde daha düşük tane verimi ( $r=-$ $0,233)$, bayrak yaprak alanı $(r=-0,365)$, daha düşük kanopi sıcaklığı ( $r=-459^{*}$ ) ve kuru madde oranı $\left(r=-439^{*}\right)$ saptanmıştır.

Trakya Bölgesinde özellikle taban arazilerde fazla yağışlı yıllarda, uzun boylu çeşitlerde, fazla tohum ve gübre kullanımının etkisi ile yatma önemli bir sorun olarak ortaya çıkmaktadır. Trakya Bölgesinde yapılan çalışmalarda bitki boyu $85-90 \mathrm{~cm}$ arasında olan çeşitlerin sap sağlamlığı ile birlikte yatmaya dayanıklılık yönünden bölgeye daha uygun olduğu görülmüştür (Anonim, 2002). Araştırmada en yüksek bitki boyu 120,3 cm ile Milena ve 119,1 cm ile Kate A-1 çeşitlerinde ölçülürken, en kısa boy $72,9 \mathrm{~cm}$ ile Golia ve $79,9 \mathrm{~cm}$ ile Trakya BVD12'de saptanmıştır. Araştırmada uzun boylu çeşitlerde düşük kanopi sıcaklığı ölçülürken, kuru madde oranının da azaldığı görülmüştür.

Başaklanma ve olgunlaşma gün sayısı bakımından yapılan değerlendirmede çeşitler arasında önemli farklılık olduğu görülmüştür. Trakya Bölgesi'nde son yıllarda özellikle Mayıs ayındaki yağış düşüklüğü ve düzensizliği başaklanması geç olan, tane dolum süresi Mayıs ayının ikinci yarısında gerçekleşen çeşitleri daha çok etkilemektedir. Bu nedenle bölgede genellikle erkenci veya orta erkenci çeşitler tercih edilmektedir. Araştırmada yer alan çeşitler ortalamada 125,2 günde başaklanmıştır Araştırmada en erken başaklanma 117,3 gün ile Golia ve 118,5 gün ile Guadalupe çeşitlerinde belirlenirken, 131,4 gün ile Milena ve 130,6 gün ile Krasunia ve 130,3 gün ile Aglika en geç başaklanan çeşitler olmuştur. Araştırmada genotiplerin olgunlaşma süreleri 157,3 ile 169,0 gün arasında değişirken deneme ortalaması 163,9 gün olarak tespit edilmiştir. Araştırmada en erken fizyolojik olgunluk Golia, Aldane ve Kate A- 
1 çeşitlerinde belirlenirken, en geç olgunlaşma Trakya BVD12 ve Milena çeşitlerinde saptanmıştır.

\section{Sonuç}

Araştırmada verim potansiyeline göre Trakya BVD7, Tina, Nina, Syrena, Selimiye ve Bereket öne çıkan çeşitler olurken, araştırmada incelenen diğer bazı (Prostor, Gelibolu, Esperia, Golia, Guadalupe) çeşitlerin de yüksek verim potansiyeline sahip olduğu görülmüştür. araştırmada incelenen karakterlerde çeşitler arasında önemli farklılık bulunmuştur. Araştırmada uzun boylu çeşitler ve geççi çeşitlerde daha düşük kanopi sıcaklığı ölçülürken, erkenci ve kısa boylu çeşitlerde daha yüksek kanopi sıcaklığı ölçülmüştür. Ayrıca yaprak su tutma kapasitesindeki artış ile klorofil miktarının fazla olması kanopi sıcaklığını düşürmüştür.

Araştırmada incelenen diğer karakterlerden uzun boylu çeşitlerde daha yüksek yaprak su tutma kapasitesi ve bayrak yaprakta ölçülen klorofil miktarının yüksek olduğu belirlenmiştir. Araştırmada değerlendirilen kısa boylu çeşitlerin verim potansiyelinin daha yüksek olduğu görülmüştür. Ayrıca uzun boylu çeşitlerin daha düşük bayrak yaprak alanı ve kuru madde oranına sahip olduğu saptanmıştır.

Özetle araştırmada incelenen çeşitlerin çoğunluğunun verim potansiyelinin yüksek olmasından dolayı incelenen karakterler ile verim arasında ilişki beklenen seviyede olmamıştır. Bayrak yaprak alanı, kanopi sıcaklığı, klorofil miktarı, yaprak su tutma kapasitesi gibi fizyolojik parametrelerin verimle ilişkisinin kuraklık stresi koşullarında yapılması halinde beklenen ilişkilerin saptanması mümkün olacaktır. Çeşitlerde bayrak yaprak alanının artması kanopi sıcaklığını artırırken, uzun boylu ve geççi çeşitlerde daha düşük kanopi sıcaklığı ölçülmüştür. Yaprak su miktarının artışı klorofil miktarını da artırmıştır.

\section{Kaynaklar}

Adamsen F.J., Pinter P.J., Barnes E.M., Lamorte R.L., Wall G.W., Leavitt S.W., Kimball B.A., 1999. Measuring Wheat Senescence with a Digital Camera. Crop Ecology, Production and Management. Crop. Sci., 39: 719-724.

Anonim, 2002. Ülkesel Serin İklim Tahılları Araştırma Projesi. 2002 Yılı Araştırma Projeleri Raporu. Edirne. (Basılmamış)
Anonim, 2011. Ülkesel Serin İklim Tahılları Araştırma Projesi. 2011 Yılı Araştırma Projeleri Raporu. Edirne. (Basılmamış)

Başer I., Korkut K.Z. ve Bilgin O. 2005. Ekmeklik buğdayda (Triticum aestivum L. ) kurağa dayanıklılıkla ilgili özellikler arasındaki ilişkiler. Tekirdağ Ziraat Fakültesi Dergisi 2 (3): 253259.

Blum A., Shpıler L., Golan G., Mayer J., 1989. Yield Stability and Canopy Temperature of Wheat Genotypes under Drought-Stress. Field Crop Research, 22: 289-296.

Clarke J.M, 1982. Use of physiological and morphological traits in breeding programmes to improve drought resistance of cereals. Drought Tolerance in Winter Cereals. Proceed Of An Int. Workshop 27-31 October Capri, Italy.

Eberhart S.A. and Russel W.A. 1966. Stability Parameters for Comparing Varieties. Crop Science, 6: 36-40.

Finlay K.W., Wilkinson G.N. 1963. The Analysis of Adaptation in a Plant Breeding Programme. Aust. J. Agric.Res., 14: 742-754.

Jackson R.D Idso S.B., Reginato R.J., Pinter P.J., 1981. Canopy Temperature as a Crop Water Stress Indicator. Water Resources Research, Vol. 17, No. 4 Page: 1133-1138.

Kalaycı M., 2005. Örneklerle Jump Kullanımı ve Tarımsal Araştırma için Varyans Analiz Modelleri. Anadolu Tar. Araştırma Enst. Müd. Yayınları, Yayın No: 21, Eskişehir.

Öztürk I ve Korkut Z. K., 2011. Ekmeklik Buğday (Triticum aestivum L.) Genotiplerinde Kurağa Dayanıklılığın Karakterizasyonu Ve Kalite İle İlişkileri, Doktora Tezi. Namık Kemal Üni., Fen Bilimleri Enst. Tekirdağ

Reynolds M.P., Nagarajan S., Razzaque M.A., Ageeb O.A.A., 2001. Heat Tolerance. Applicationof Physioloji in Wheat Breeding, Chapter 10, p.124-135. International Maize and Wheat Imp. Center, CIMMYT. Mexico.

Soylu S. ve Sade B., 2000. Makarnalık buğdaylarda (Triticum durum L.) başaklanma süresi ve kışa dayanıklıı̆ın kombinasyon yeteneği, melez gücü ve kalıtımı. Konya, S.Ü. Ziraat Fakültesi Dergisi, cilt 14; sayı 23, sayfa:120-130

Van Ginkel M., Reynolds M., Trethowan R., Hernandez E., 2004. Can canopy temperature depression measurements help breeders in selecting for yield in wheat under irrigated production conditions? http://www.cropscience.org.au/icsc2004/post er/3/4/6/1353vanginkelm.htm 